\title{
Sistem Pendukung Keputusan Pengangkatan Karyawan Tetap Pt. Triagung Abadi Menggunakan Metode Analytical Hierarchy Procces
} (Ahp)

\section{Article Info}

Article history:

Received Feb 27, 2021

Revised Mar 16, 2021

Accepted Apr 01, 2021

\section{Keywords:}

Decision support system, AHP

Method, Employee Appointment

\begin{abstract}
The development of information technology today requires fast and accurate information in its implementation. The appointment of employees who perform well with the support of a decision support system is one of the implementations of the development of information technology. Research that uses the AHP method in this decision support system produces an application for an appointment decision support system that can be used in companies. The criteria used in the decision support system for the appointment of employees are: Quality of work of employees. The results of this study are to produce a ranking order of prospective employees who have good performance who have been selected, and the output of the application can assist decision makers in choosing alternative employee appointments. The application in this research is implemented using the VB programming language. NET 2008 and databases using Mysql. The Analytical Hierarchy Process (AHP) method is a method used in the design of a decision support system. The concept used by the AHP method is to change the value of a qualitative Decision Support System into a quantitative value. So that the decisions taken can be more objective. By using this Analytical Hierarchy Process, it is hoped that the employee appointment process will be more effective and efficient so that the company's leaders quickly get the value of employees who will be appointed as permanent employees to get the expected results.
\end{abstract}

This is an open access article under the CC BY-SA license.

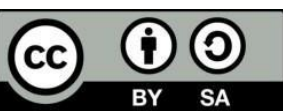

\section{Corresponding Author:}

Putri Permata Sari

Ganesha Polytechnic, Informatics Management, Medan, Indonesia

Email Address: Putrisyahdal7@gmail.com

(C) 2021 The Author: Published by. Cattleya Darmaya Fortuna

\section{Pendahuluan}

Sumber Daya Manusia (SDM) merupakan salah satu aset berharga yang dimiliki oleh setiap perusahaan. Pengelolaan SDM memerlukan standarisasi yang jelas agar 


\section{Putri Permata Sari}

doi.org/10.54209/jatilima. V3i1.144

dapat memberikan konstribusi yang positif bagi suatu perusahaan atau organisasi [1]. Dalam meningkatkan mutu sumber daya manusia yang berkualitas harus ditunjang dari sisi sumber daya manusia itu sendiri [2]. Ketersediaan sumber daya manusia di Indonesia cukup tinggi, namun karena pentingnya sumber daya manusia pada suatu perusahaan menyebabkan keselektifan perusahaan dalam memilih calon karyawannya [3]. Kualitas Sumber Daya Manusia (SDM) merupakan salah satu faktor untuk meningkatkan produktivitas kinerja suatu organisasi atau instansi [4] sedangkan karyawan adalah motor penggerak berjalannya proses bisnis dalam sebuah perusahaan [5]. Dalam pengangkatan SDM perlu adanya penilaian - penilaian untuk mengetahui layak atau tidaknya SDM tersebut bekerja pada perusahaan [6], sementara proses penilaian penerimaan karyawan menghabiskan banyak waktu dan penilaian dilakukan masih secara subjektif [7]. Pengangkatan Karyawan yang berkinerja baik dan memenuhi kriteria dengan dukungan sistem pendukung keputusan merupakan salah satu implementasi perkembangan teknologi informasi [8]. Sistem pendukung keputusan merupakan suatu sistem yang mampu memecahkan masalah secara efesian, efektif, yang bertujuan untuk membantu pengambilan keputusan dengan memilih berbagai alternatif keputusan [9]. Sistem pendukung keputusan memberikan suatu keputusan yang bersifat semiterstruktur, dimana tidak seorangpun tahu secara pasti bagaimana keputusan seharusnya dibuat [10]. SPK bertujuan untuk menyediakan informasi, membimbing, memberikan prediksi serta mengarahkan kepada pengguna informasi agar dapat melakukan pengambilan keputusan dengan lebih baik [11]. SPK yang dibangun pada riset ini diharapkan mampu menghasilkan rekomendasi dengan memberikan perankingan lokasi kepada pengguna sesuai preferensinya [12]. Metode AHP yaitu suatu metode yang input utamanya adalah persepsi manusia [13]. AHP digunakan untuk memberikan pembobotan pada masing-masing kriteria [14] dan untuk menentukan tingkat kepentingan dari variabel - variabel [15].

\section{Metode}

Metode yang digunakan dalam penelitian ini adalah untuk mempermudah pihak perusahaan dalam menentukan karyawan tetap.

1. Pengumpulan data

Penelitian ini dilakukan dengan mengumpulkan data dari sumber yang akurat dan jelas, yaitu:

a. Pengamatan Melakukan pengamatan langsung terhadap proses penetapan pegawai biasa menjadi pegawai tetap.

b. Wawancara Proses wawancara dilakukan untuk menghasilkan data yang akurat tentang cara menentukan karyawan tetap untuk menjadi karyawan tetap di perusahaan.

c. Tinjauan Literatur Penelitian dilakukan dengan mencari referensi seperti buku, jurnal dan lain-lain untuk memudahkan penelitian.

2. Analisis data

Analisis data merupakan suatu langkah yang dilakukan untuk menjadikan data yang telah diperoleh, dikelola untuk menghasilkan data yang baik untuk kepentingan perusahaan dalam menentukan pegawai tetap yang memiliki kompetensi dalam mengembangkan perusahaan. 


\section{Putri Permata Sari}

doi.org/10.54209/jatilima. V3i1.144

a. Penerapan Metode Dalam penelitian ini peranan metode merupakan hal yang paling penting untuk menghasilkan keputusan yang lebih efektif, oleh karena itu hasil penelitian disesuaikan dengan perhitungan metode tersebut.

b. Perancangan yang dirancang sesuai dengan model yang diharapkan dengan kebutuhan swalayan kedepan secara bersama-sama sehingga sistem bekerja lebih efektif.

c. Pengujian Aplikasi,Lihat apakah aplikasi berjalan dengan baik atau tidak dengan pengujian untuk setiap form yang ada di aplikasi.

d. Implementasi DSS, Setelah menguji aplikasi, langkah selanjutnya adalah menerapkan metode pada aplikasi apakah aplikasi memenuhi harapan.

\section{Analisa dan Pembahasan}

Sebelum melakukan proses persetujuan dan pengangkatan status, pihak perusahaan harus melakukan analisa terlebih dahulu kepada karyawan kontrak dengan memperhatikan faktor 6C. Mengidentifikasi Kriteria Penilaian Berdasarkan identifikasi masalah yang dilakukan maka perlu dilakukan identifikasi serangkaian kriteria penilaian. Kriteria penilaian yang dicari adalah apa yang menjadi dasar dalam pengambilan keputusan. Kriteria dalam pengambilan keputusan menentukan status karyawan kontrak menjadi karyawan tetap adalah sebagai berikut:

\begin{tabular}{cc}
\multicolumn{2}{c}{ Tabel 1. Penilaian } \\
\hline Kriteria & Penilain \\
\hline C1 & Kedisiplinan \\
C2 & Prestasi Kerja \\
C3 & Pengalamam Kerja \\
C4 & Perilaku \\
\hline
\end{tabular}
5, yaitu:

Ranking kecocokan setiap alternatif pada setiap kriteria, dinilai dengan 1 sampai Tabel 2. Ranking

\begin{tabular}{cc}
\hline Ranking & Keterangan \\
\hline 1 & Kurang \\
2 & Cukup \\
3 & Baik \\
\hline
\end{tabular}

Data Bobot Kriteria ditentukan oleh pihak PT. Tri Agung Abadi dengan jumlah bobot kriteria 100. Adapun tabel bobot kriteria sebagai berikut:

Tabel 3. Bobot Kriteria

\begin{tabular}{cc}
\hline Kriteria & Penilain \\
\hline C1 & 15 \\
C2 & 20 \\
C3 & 10 \\
C4 & 15 \\
\hline
\end{tabular}

Adapun tabel karyawan yang akan mendapatkan penilaian adalah sebagai berikut: 


\section{Putri Permata Sari}

doi.org/10.54209/jatilima. V3i1.144

Tabel 4. Data Karyawan

\begin{tabular}{cccccc}
\hline \multirow{2}{*}{ NIK } & \multirow{2}{*}{ NAMA } & \multicolumn{4}{c}{ Kriteria (Bobot) } \\
& & C1 & C2 & C3 & C4 \\
\hline 458843 & Fajrul & 75 & 75 & 75 & 80 \\
434349 & Fadillah & 80 & 80 & 90 & 75 \\
493489 & Wili & 75 & 80 & 80 & 0 \\
495876 & Janter & 70 & 80 & 70 & 60 \\
4762893 & James & 75 & 80 & 75 & 60 \\
\hline
\end{tabular}

\section{Implementasi Program}

Pengujian metode berfokus pada tindakan pengguna yang terlihat dan pengguna dapat mengenali output dari sistem, pengujian ini menjalankan sistem pada lingkungan yang aktif dengan menggunakan data yang benar. Pada tahap ini pengujian hanya sebagai administrator yang memiliki hak akses sepenuhnya pada sistem.

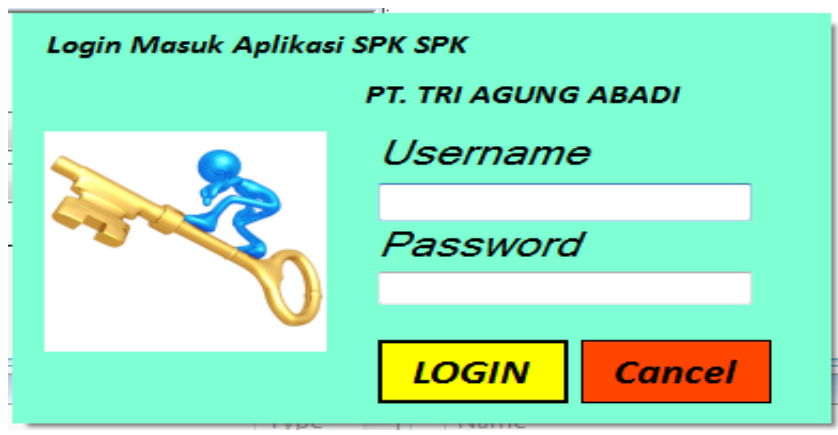

Gambar 1. Form Login

Form ini digunakan agar User dapat mengakses program jika nama dan passwordnya benar.

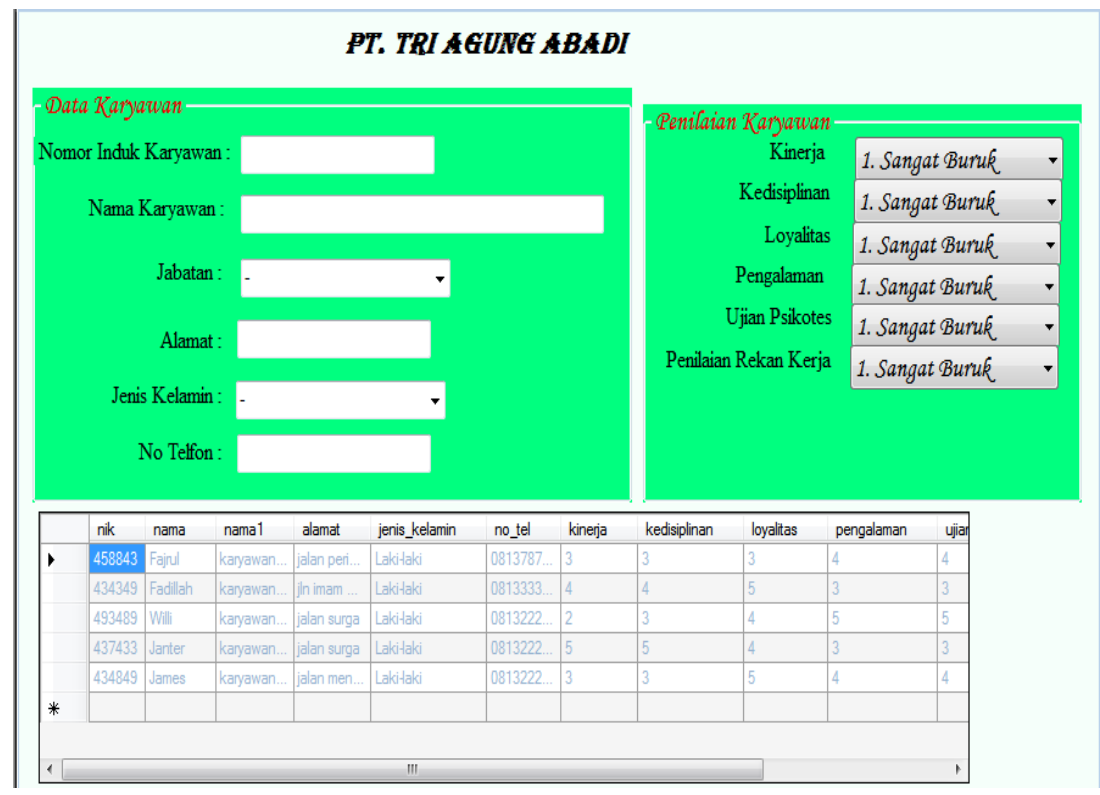

Gambar 2. Form Data Karyawan

Form karyawan digunakan untuk melakukan kegiatan manipulasi terhadap data 


\section{Putri Permata Sari}

doi.org/10.54209/jatilima. V3i1.144

karyawan. Seperti penambahan karyawan, penghapusan dan perubahan data karyawan dan form karyawan juga berfungsi sebagai form inputan penilaian karyawan.

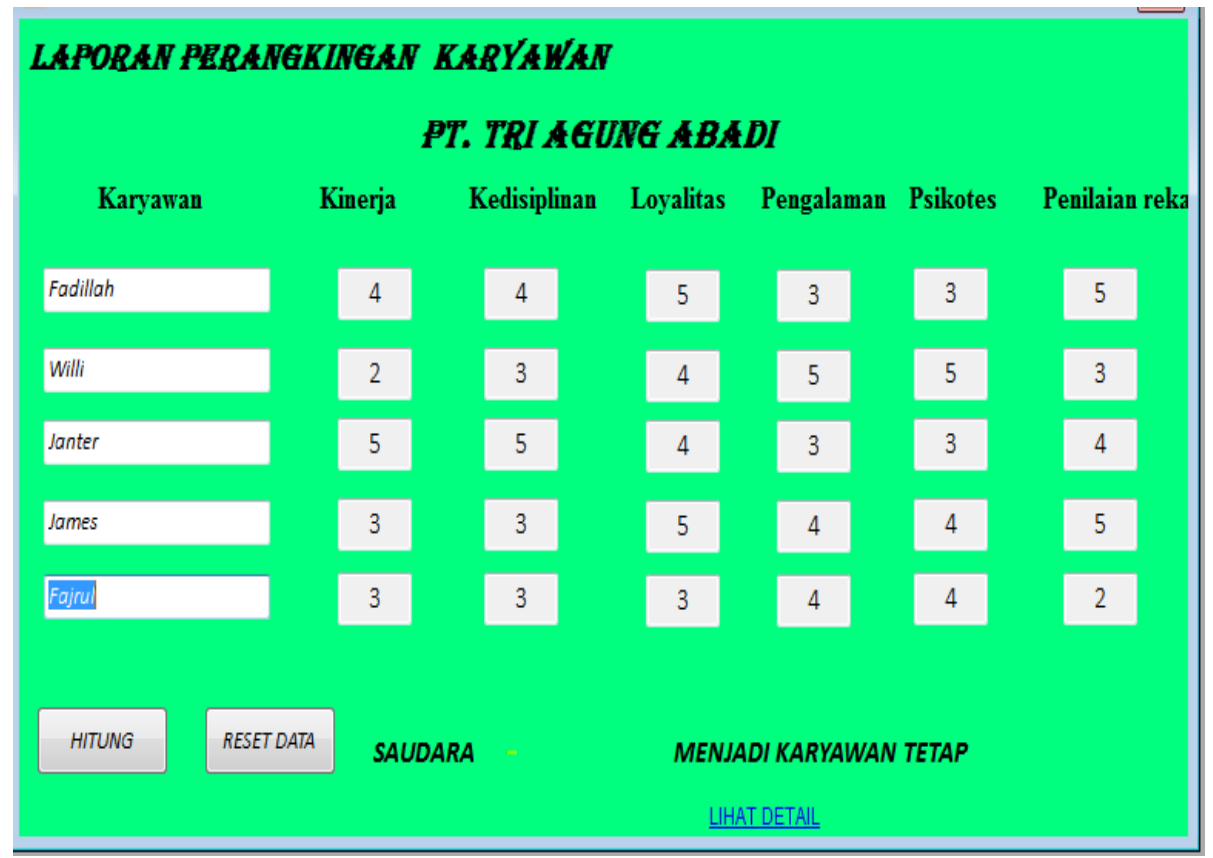

Gambar 3. Form Laporan Perangkingan

Form laporan perangkingan merupakan Proses dari metode Sistem pengambilan kmeputusan dari metode Analythical Hierarki Process $(A H P)$, menu inı merupakan tampilan berguna untuk melakukan proses penilaian.

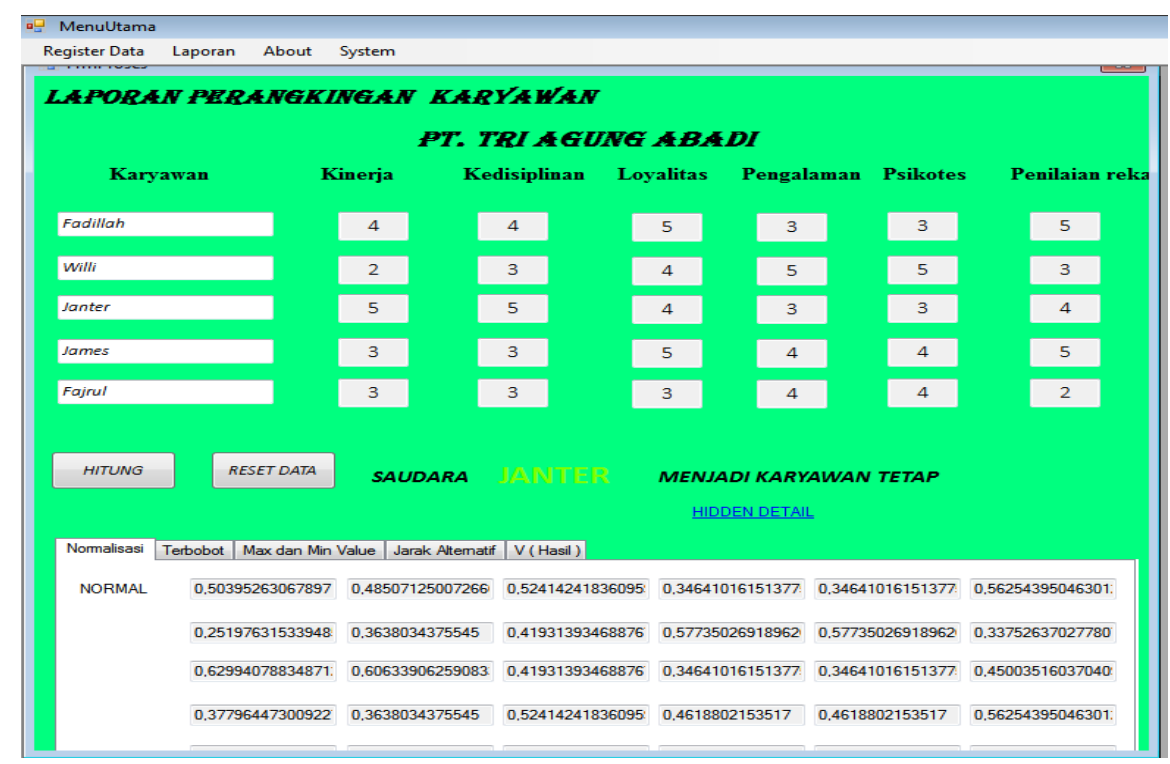

Gambar 4. Matriks Ternormalisasi

Matriks normalisasi ternormalisasi berfungsi untuk mendapatkan nilai yang sebanding dari satu data dengan data yang lainnya. Dalam hal ini calon karyawan tetap yang dinormalisasikan dimasukkan kedalam matriks nilai masing-masing kriteria tiap karyawan dibagi dengan jumlah pada tiap kriteria. Sehingga didapatkan nilai 


\section{Putri Permata Sari}

doi.org/10.54209/jatilima. V3i1.144

ternormalisasi tiap kriteria pada masing-masing karyawan.

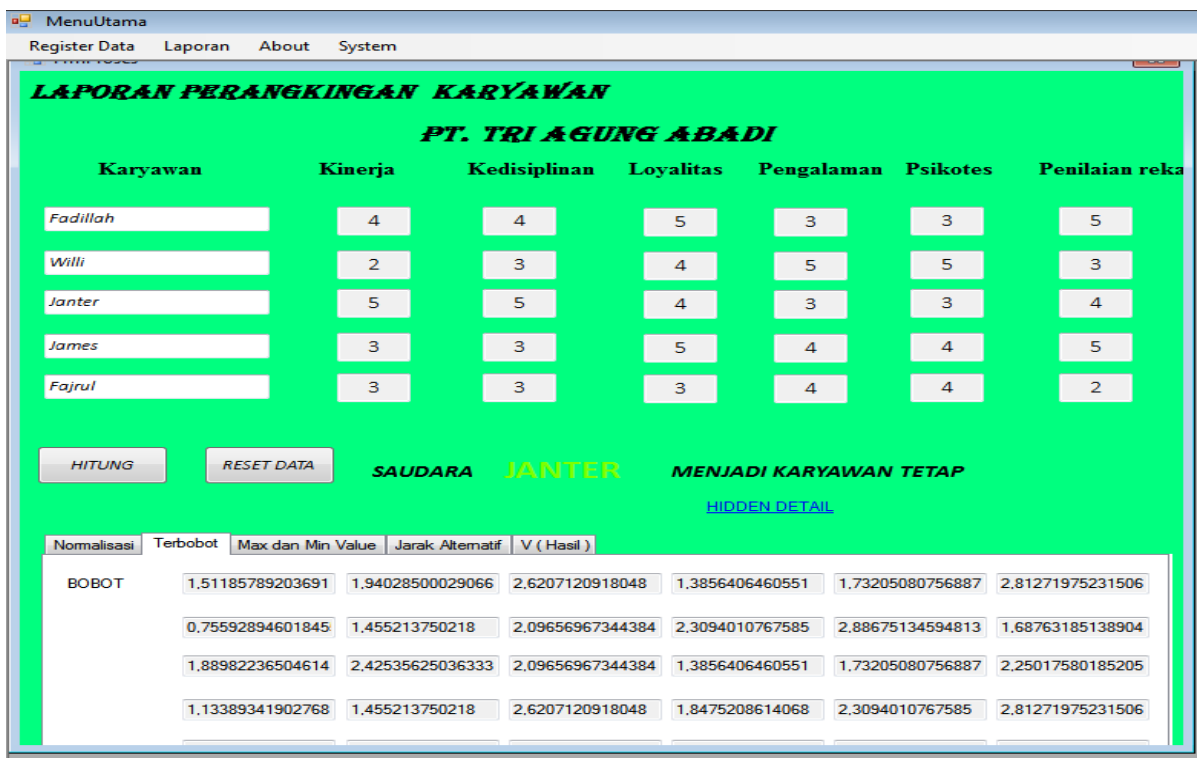

Gambar 5. Matriks Keputusan Terbobot

Matriks keputusan terbobot merupakan hasil kali dari bobot kriteria yang telah ditentukan dengan besar hasil nilai yang didapatkan dari perhitungan normalisasi matriks keputusan.

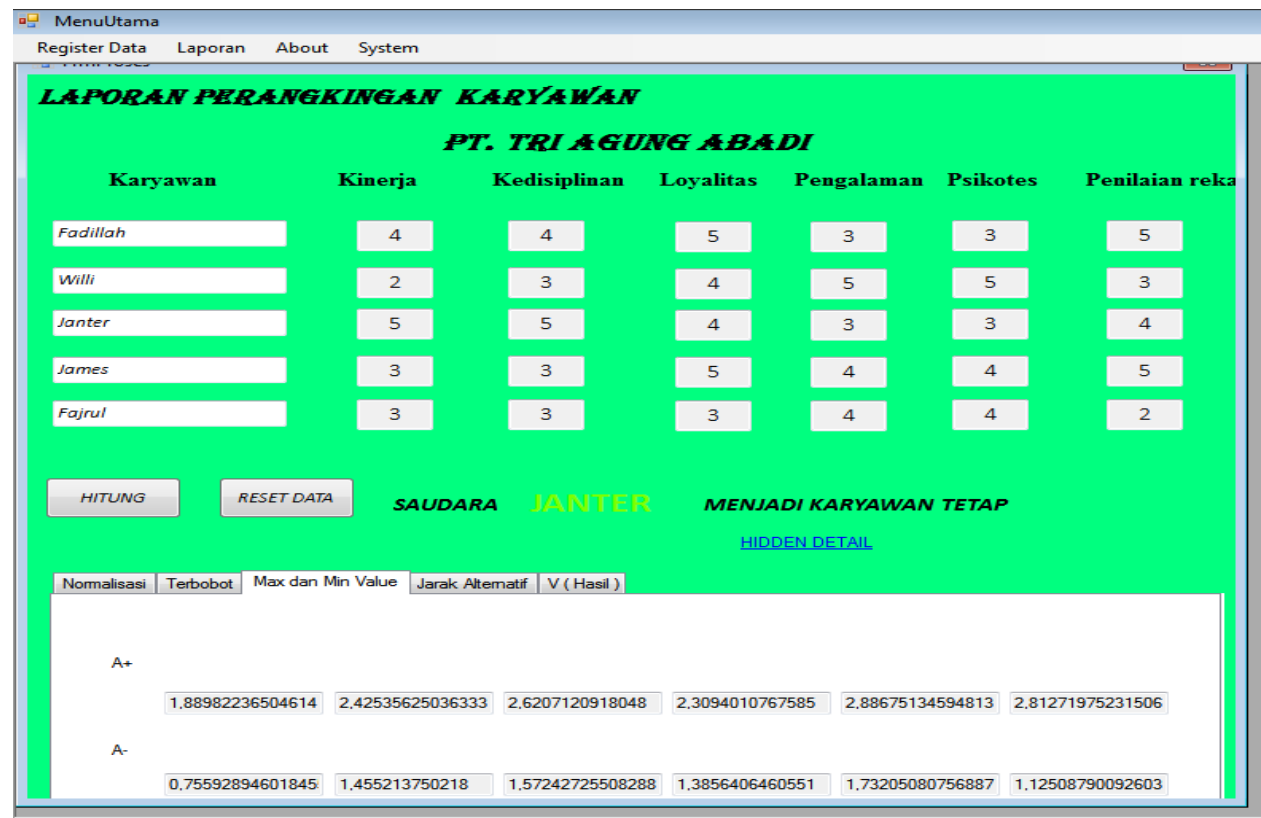

Gambar 6. Matriks Solusi Ideal Positif dan Solusi Ideal Negatif

Solusi ideal positif dan negatif dapat ditentukan berdasarkan nilai matriks normalisasi bobot. Solusi ideal positif merupakan nilai tertinggi dari setiap atribut matriks normalisasi bobot. Sedangkan solusi ideal negatif diperoleh dari nilai terendah dari setiap atribut matriks normalisasi bobot. 


\section{Putri Permata Sari}

doi.org/10.54209/jatilima. V3i1.144

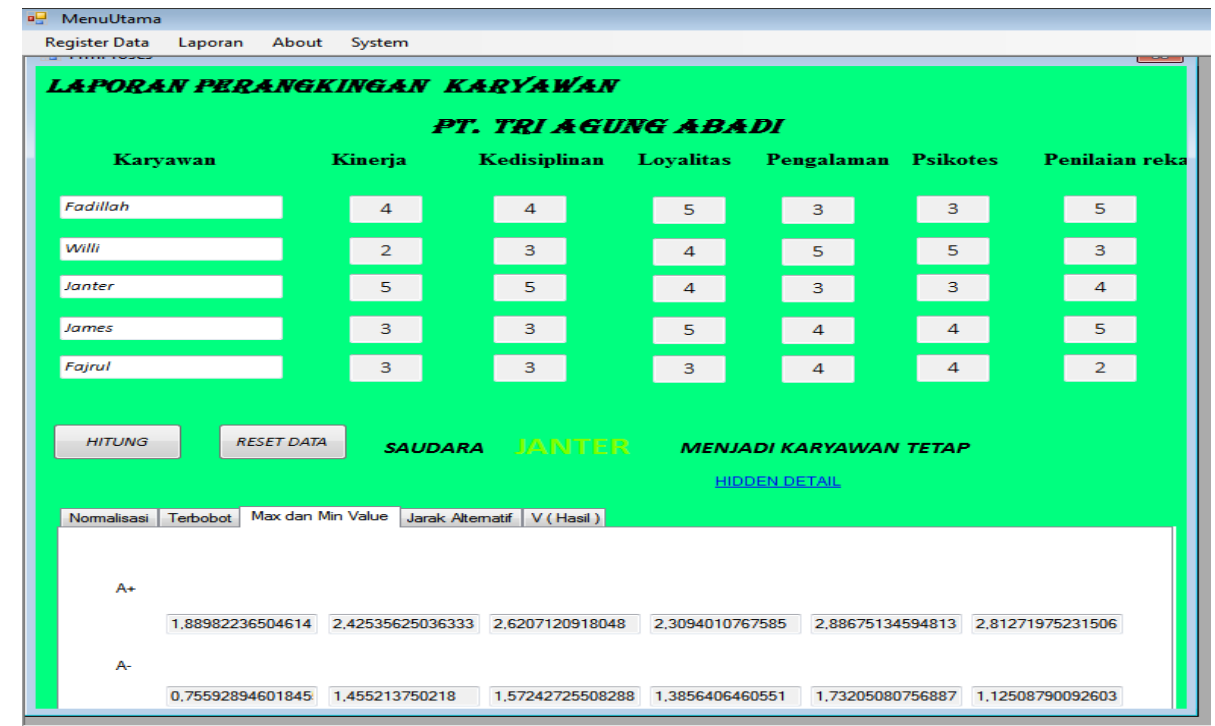

Gambar 7. Nilai Preferensi

Perhitungan nilai preferensi digunakan untuk mendapatkan nilai akhir dari masingmasing karyawan.

\section{Kesimpulan}

Sistem Pendukung Keputusan Pengangkatan Karyawan Tetap Dengan Menggunakan Metode Analytical Hierarchy Process (AHP) ini merupakan salah satu solusi untuk meningkatkan efisiensi dan efektifitas proses pengangkatan karyawan. Sistem ini dapat membantu PT. Triagung Abadi dalam memberikan gambaran pada pendukung keputusan perusahaan dalam menilai karyawan. Penulis menarik kesimpulan sebagai berikut: Lebih tepat untuk menyelesaikan penilaian kriteria-kriteria pengangkatan karyawan tetap pada PT. Triagung Abadi. Implementasi metode Metode Analytical Hierarchy Process (AHP) dalam pengangkatan karyawan tetap memiliki kelemahan dalam pengangkatan karyawan tetap pada PT. Triagung Abadi tidak biasa digunakan untuk melakukan penilaian jika yang dinilai hanya satu calon karyawan. Faktor yang mempengaruhi hasil perhitungan dengan menggunakan metode Analytical Hierarchy Process (AHP) adalah merancang sistem pendukung keputusan untuk pengangkatan calon karyawan tetap.

\section{Reference}

[1] A. A. G. Pratiwi, L. Septiana, and I. Spriadi, "Penerapan Metode Fuzzy Simple Additive Weighting (SAW) Untuk Pengangkatan Karyawan Kontrak Pada PT. Aranad Karya Saranatama," Inti Nusa Mandiri, vol. 13, no. 1, 2018.

[2] M. Marcania, "Prediksi pengangkatan karyawan dengan metode klasifiksi algoritma c5.0 (studi kasus pt. kiyokuni indonesia factory-2)," Thesist, vol. 0, 2019.

[3] Z. Hakim, A. Sudiarjo, and R. Efrida, "Rancangan Sistem Penunjang Keputusan Pengangkatan Karyawan Tetap Dengan Metode Profile Matching di PT. Lotte 


\section{Putri Permata Sari}

doi.org/10.54209/jatilima. V3i1.144

Packaging," J. Sisfotek Glob., vol. 7, no. 2, 2017.

[4] F. Rachmawati, "Analisis Algoritma C4.5 Untuk Pengangkatan Karyawan Tetap Studi Kasus PT Citra Abadi Sejati Bogor," Teknois J. Ilm. Teknol. Inf. dan Sains, vol. 6, no. 2, 2019.

[5] J. T. Informatika et al., "Sistem Pendukung Keputusan Pengangkatan Karyawan Tetap Menggunakan Metode Analytic Hierachy Process," J. Teknol. Inform. dan Komput., vol. 6, no. 1, 2020.

[6] I. Setiawati and K. Kosim, "Sistem Pendukung Keputusan Untuk Menentukan Pengangkatan Karyawan Menggunakan Metode Profile Matching," J. Ilm. Intech Inf. Technol. J. UMUS, vol. 1, no. 01, 2019.

[7] Marlince, "Aplikasi Penentuan Karyawan Terbaik Metode AHP dan Metode Promethee," Jusikom Prima, vol. 1, no. 2, 2018.

[8] Dedi, Z. Hakim, and W. Kritian, "Sistem Pendukung Keputusan Pengangkatan Karyawan Berdasarkan Hasil Evaluasi Masa Percobaan," J. Sisfotek Glob., vol. 6, no. 2, 2016.

[9] Sriani and R. A. Putri, "Analisa Sistem Pendukung Keputusan Menggunakan Metode Topsis Untuk Sistem Penerimaan Pegawai Pada Sma Al Washliyah Tanjung Morawa," J. Ilmu Komput. dan Inform., vol. 02, no. April, 2018.

[10] F. I.-R. P. Computer, "Sistem Pendukung Keputusan Penerimaan Jurnalis Menerapkan MultiObjective Optimization On The Basis Of Ratio Analysis (MOORA)," JURIKOM (Jurnal Ris. Komputer), vol. 5, no. 1, 2018.

[11] S. W. Sari and B. Purba, "Sistem Pendukung Keputusan Pemilihan Ketua Danru Terbaik Menggunakan Metode ARAS," Semin. Nas. Teknol. Komput. Sains SAINTEKS 2019, 2019.

[12] P. A. W. Santiary, P. I. Ciptayani, N. G. A. P. H. Saptarini, and I. K. Swardika, "Sistem Pendukung Keputusan Penentuan Lokasi Wisata dengan Metode Topsis," J. Teknol. Inf. dan Ilmu Komput., vol. 5, no. 5, 2018.

[13] G. P. Sanyoto, R. I. Handayani, and E. Widanengsih, "Sistem Pendukung Keputusan Pemilihan Laptop Untuk Kebutuhan Operasional Dengan Metode AHP (Studi Kasus: Direktorat Pembinaan Kursus Dan Pelatihan Kemdikbud)," J. Pilar Nusa Mandiri, vol. 13, no. 2, 2017.

[14] G. S. Mahendra and K. Y. Ernanda Aryanto, "SPK Penentuan Lokasi ATM Menggunakan Metode AHP dan SAW," J. Nas. Teknol. dan Sist. Inf., vol. 5, no. $1,2019$.

[15] I. B. Rianto and E. B. Santoso, "Penentuan Lokasi Kawasan Industri Tekstil Terpadu di Kabupaten Majalengka," J. Tek. ITS, vol. 7, no. 1, 2018. 